\title{
Living Concrete/Carrot City: An exhibition platform as a growing medium
}

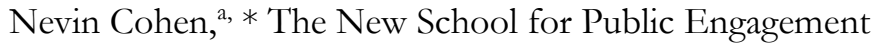 \\ Radhika Subramaniam, ${ }^{\mathrm{b}}$ Parsons The New School for Design
}

Submitted 20 December 2011 / Revised 27 March and 15 April 2012 / Accepted 16 April 2012 / Published online 11 June 2012

Citation: Cohen, N., \& Subramaniam, R. (2012). Living Concrete/Carrot City: An exhibition platform

as a growing medium. Journal of Agriculture, Food Systems, and Community Development, 2(3), 91-102.

http://dx.doi.org/10.5304/jafscd.2012.023.012

Copyright (C) 2012 by New Leaf Associates, Inc.

\begin{abstract}
The authors of this paper co-curated Living Concrete/Carrot City, an exhibition at The New School during the Fall 2010 semester that explored the relationship between urban agriculture and the city, and the roles of farmers and gardeners, designers, artists, activists, academics, and others in integrating food and agriculture into everyday city life. This reflective essay discusses the genesis of the exhibition, our curatorial decisions, and the interactions among students, faculty, and community members that we observed within the gallery. The project supported university goals of cross-

\footnotetext{
a, * Corresponding author: Nevin Cohen, Assistant Professor, Environmental Studies; The New School for Public Engagement; 72 Fifth Avenue, Room 518; New York, NY 10011 USA; nevincohen@gmail.com

b Radhika Subramaniam, Assistant Professor, Art \& Design History and Theory; Director and Chief Curator, Sheila C. Johnson Design Center; Parsons The New School for Design; 2 West 13th Street, Room Z101; New York, NY 10011 USA; subramar@newschool.edu
}

disciplinary and public scholarship, created a space for members of the urban agriculture community to learn from each other, and demonstrated the potential for an exhibition platform to serve as a vehicle for liberal arts and design schools to engage in food systems research, teaching, design practice, and public engagement. While the essay focuses on the specific instance of this exhibition and interdisciplinary collaboration, it suggests some implications for consideration by other urban institutions of higher education.

\section{Keywords}

civic agriculture, exhibition platform, pedagogy, urban agriculture

\section{Introduction}

Visitors who walked into a gallery at the heart of The New School campus in Fall 2010 found themselves greeted by the buzz of Nova Scotia bees. These field recordings were to be found once more in a sound composition farther within the gallery that explored the potential impact of human com- 
munication technologies on colony collapse disorder. ${ }^{1}$ That summer, New York City had lifted the ban on beekeeping, and beaming in over the web, in perfect legality, was a live feed of rooftop hives in Brooklyn. The coalescence of interest around bees represented in the gallery was part of Living Concrete/Carrot City, a semester-long exhibition platform that we cocurated at the Sheila C. Johnson Design Center (SJDC) at Parsons The New School for Design. ${ }^{2}$

As the portmanteau title suggests, the exhibition had its genesis in an exchange. Dr. Joseph Nasr from Ryerson University, Canada, was appointed as a visiting fellow at The New School during the Spring 2010 semester. He had recently co-curated Carrot City, a traveling exhibition about the intersection of design and urban agriculture, ${ }^{3}$ and his residence at The New School encouraged us to work together to include a selection of the Carrot City exhibits in a larger exhibition.

An important source of inspiration for Living Concrete, as we titled the New School exhibition, was the fact that across the university, food systems research, teaching, and practice occurred in programs not connected to food studies or agriculture. Liberal arts and design majors, as well as graduate students in urban and environmental policy, were increasingly taking food studies courses and doing internships on urban farms, in

${ }^{1}$ A recording of the composition is available at http://melissagrey.net/index.php?/sounds/sprawl-colony/

2 The term 'platform,' derived from digital media and design, is used in contemporary curatorial practice to designate forms of mediation, research and discussion that present cultural artifacts through collaborative and thematic structures.

${ }^{3}$ Carrot City was co-curated by Joe Nasr, June Komisar, and Mark Gorgolewski.
Photo: Nevin Cohen

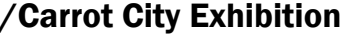
and and and school garden programs, and with food policy organizations. Yet these varied, multidimensional, food-related scholarly activities were dispersed throughout the university without coordination or opportunities for collaboration. A major impetus for the exhibition was to bring these colleagues and their work together, and to provide a place for them to identify interconnected interests.

The exhibition also dovetailed with the mission of the SJDC, which actively promotes a dialogue on the role of art and design in responding to the contemporary world. Provoked by current environmental and social challenges, its curatorial agenda reflects and advances creative research and pedagogic practices. The exhibitions and public programs in its two galleries encourage an interdisciplinary examination of possibility and process, blurring the boundaries between classroom, laboratory, studio, and exhibition, and link the university to local and global debates. For a new center under new leadership, the exhibition represented an important opportunity to model a curatorial framework in which the gallery could be more than the sum of its white walls, fostering for the university and beyond a creative and socially engaged aesthetic practice. 
We chose to focus on urban agriculture for several interconnected reasons. The recent interest in urban agriculture in cities throughout North America has been a response to various global and local-scale crises, and serves to educate and politicize people about food systems inequities and the precariousness of conventional agriculture (McClintock, 2010; Morgan \& Sonnino, 2010). Significant racial and class disparities exist within the food system, including New York City's urban agriculture communities, and an increasing number of communities, particularly those of color, are engaging in activism to address these injustices (Alkon \& Agyeman, 2011; Cohen \& Reynolds, 2012; Gottlieb \& Joshi, 2010). Often, urban agriculture projects are the sites of organizing to address broader food systems and community development issues, while food production is often as much a means to engage people in these broader issues as it is to put fresh vegetables on the table, especially given the limited space and short growing seasons in cities like New York. Finally, over the past few years, cities throughout North America, particularly New York City with its 1,000 community gardens and dozens of urban farms, have been in the midst of policy and planning efforts to facilitate their expansion (Hodgson, Caton Campbell, \& Bailkey, 2011).

From the start, we wanted to create an active space that would attract a wide range of urban agriculture innovators, pioneering environmentalists, educators, policy-makers, artists, social justice advocates, public scholars, community gardeners, designers, and "foodies" in the broadest sense, whose debate and discussion would enliven the gallery. We also wanted to link university faculty and students working on sustainable food system projects to the very active New York City community of food activists and urban agriculture practitioners. We hoped to explore the possibility that by weaving agriculture into the urban landscape, individuals within cities can become more closely connected to the food system through their participation in food production, and by doing so, would be better able to address various social, economic, and ecological challenges.

\section{Curatorial Approach}

The development of this exhibition represented a unique collaboration for us, as we weren't a natural fit. This necessitated a continual translation between our disciplinary contexts that influenced the modes of presentation. Nevin Cohen's research has explored the possibilities of involving citizens in urban environmental decision-making (particularly the food system), while Radhika Subramaniam's work has focused on cultures of catastrophe, particularly the creation of critical, creative interdisciplinary and dialogic platforms in such contexts. Where our research and professional practices met was around a mutual interest in fostering conversation among a diverse array of people with shared but divergent expertise in a contemporary issue: food production.

We were also keen to examine in what ways the university's roles as a research, teaching, and convening institution could impact its own urban context. From the outset, we wanted the exhibition to be an invitation, a "pre-text" for vigorous, rigorous, and omnivorous conversations about urban agriculture and related urban food systems, and not merely a didactic presentation. This emphasis on the exhibition platform as process, not display, was established right from our early planning meetings. In order to create inventories of activity, we brought together diverse faculty members - from architecture, design and technology, sociology, environmental studies, and fine arts, to name a few - to discuss their work, their teaching and possibilities for participation in Living Concrete. While not all of them produced exhibits for the show, many remained involved by bringing their classes to the gallery and to events. We hoped to attract new voices to the table with ideas, questions, provocations and creative solutions to the issues facing the food system.

The exhibition was conceived as a growing medium, providing a series of rich, open-ended platforms for discussion and dialogue. Thus Living Concrete, the collection of projects from The New School, provided the first point of conversation with the visiting Carrot City. Alongside this, we built a series of mechanisms for ongoing public engagement into the design of the space and the program; these included bulletin boards, panels, field guides, 
readers and a semesterlong mapping project tied to a course.

Using a hybrid curatorial model that embraced "the exhibition" as a framework for critical thinking and engagement, we created a series of encounters between the exhibits and programs that involved audiences in its creation. A visitor coming to the exhibition on the last day would find a different show than that at the opening, partly because of the introduction of new materials into the gallery and also because the discussions that infused the space encouraged an active transformation in debate and action. In addition, a media class live-streamed the panels online, resulting in a viewership wider than that of the gallery.

\section{Exhibition}

On display were creative, curricular, and research projects from The New School programs in environmental and food studies, design, architecture, and public policy (Living Concrete), alongside a selection of exhibits from Carrot City that explored the relationship of design and urban food systems. An underlying theme of the exhibition was the possibility that urban agriculture can function as a form of community-building, what Lyson (2004, p.2) described as "civic agriculture," or "community-based agriculture and food production activities" that also "create jobs, encourage entrepreneurship, and strengthen community identity." In curating the exhibits, we focused on examples of urban agriculture projects that functioned primarily as mechanisms for self-provisioning, financial profit, and community-building, rather than as speculative designs to substitute for commodity agriculture.
Photo: Martin Seck

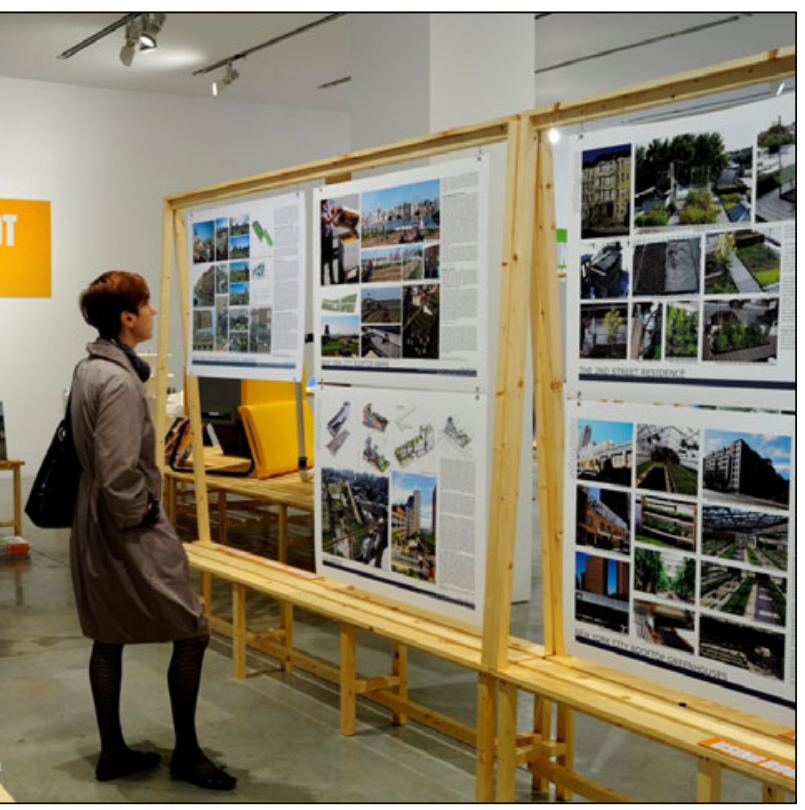

These projects were selected for their ability to address a fine-tuned sense of location, the everyday experience of place and people, and the shared responsibility to both that the practice of food production at the community scale can foster. They also demanded that designers (of the built environment, interaction designers, or policy-makers) reflect on their placement in this spectrum as participants. They demonstrated the potentials and challenges in the links between design and urban agriculture, and the ways in which the networks of food and community can be mapped and visualized (including nonhuman members of the community, as in the case of the multimedia exploration of the honeybee's role in our ecosystem).

Carrot City's cases included a mix of conceptual, speculative, and realized projects, arrayed across several scales, from citywide projects concerned with building community and knowledge, to home and rooftop projects, to a range of products — such as "growbags" (types of hanging planters), a rainwater collection system, and beehives - that support urban agriculture in all these scales. These types of projects have been included in a recently published book by the same name (Gorgolewski, Komisar, \& Nasr, 2011). 
Figure 3. Notice Board of Food and Agriculture Events

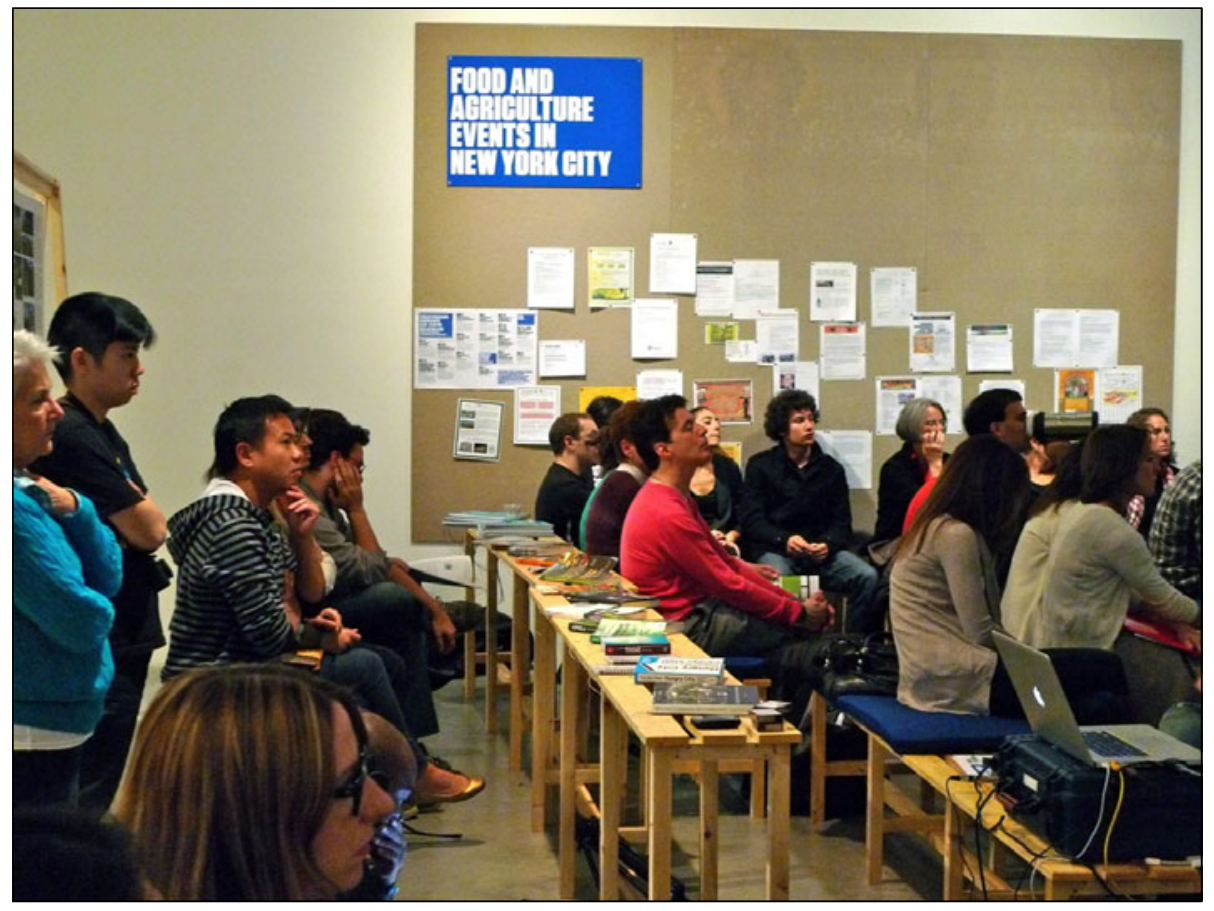

quently, knowledgeable gallery visitors took it upon themselves to scribble responses. For example, after the opening night of the exhibition, we found a flurry of back and forth discussion by attendees about composting and its regulation in the city.

The reading area contained a collection of books about urban agriculture, field guides and urban agriculture walking tour guides, as well as readers that provided relevant background articles for each weekly panel discussion. A monitor showed two short videos made by The New School

The third element of the exhibition, the public platform, was reflected in the design of the exhibition created by Manuel Miranda and Jiwon Lee. Using a series of simple fruit crate-style wooden display units, the gallery was divided into three broad zones, one of which was a platform for public pedagogy: a flexible space to host lectures, readings, panels, classes, or to function as a place for reading and reflection. Two walls of the gallery and a reading area were designed to be collaborative spaces to share information. On one wall we installed a notice board for the constant stream of public events about urban food systems happening in New York City. This grew into a colorful patchwork of event posters, announcements, calls to advocacy, and, in the aftermath of a freak hailstorm that fall, a rally to help some of the affected farms in Brooklyn. Another wall featured a question-andanswer bulletin board that allowed gallery visitors to post questions about urban agriculture to be answered by The New School faculty and students, with the help of experts from the community. ${ }^{4}$ Fre-

\footnotetext{
${ }^{4}$ Questions ran the gamut from volunteering, soil contamination in city backyards, distinctions between farm
}

students about local farming initiatives. At lunchtime, in collaboration with Food Studies professor Fabio Parasecoli, we held a series of works-in-progress presentations at brown bag lunches by faculty and students discussing their teaching and research projects. At other times, the benches and reading tables allowed visitors to spend time perusing materials.

It was important to us that this "platform for public pedagogy," should not simply mimic a classroom or lecture hall. The raw, lightweight, cratelike look of the furniture designed for it was meant to evoke a roll-your-sleeves-up, workman-like approach. The benches for seating could transform easily into a temporary display table for models, or into a table for a live-stream computer set-up and for taking notes. The monitor showing videos would become a presentation screen when there were speakers leading discussions. At the end of the year, students who had created food-related projects in a class had their final presentations and

shares and community supported agriculture, and the financing of rooftop farms, to the impact of the large-scale adoption of urban farming on capitalism in America. 
review in the gallery, leaving the designs (and some recipes) on display on one of the tables. With this porosity between studio, research and scholarship, community engagement, and professional expertise, we hoped Living Concrete would act as what artist Joseph Beuys called a "social sculpture," (Tisdall, 1979) a beehive of collaborative, creative, and evolving social dialogue (see Snider, 2010).

\section{Living Concrete Exbibits}

Living Concrete featured projects that were inherently exploratory, demonstrating moments of critique and learning through which we intended to convene shared interests as a means of education rather than to attempt to suggest exemplary designs. We wanted to unseat any conception of the gallery or the university as sites of display and mastery, and convey that these exhibits were instances in an ongoing process of research, debate, and engagement.

For instance, we included a set of student videos outlining design interventions in a city bodega not because of their innovative solutions, but because they reflected a keen awareness of the complexity of co-design, particularly the complications that arise with interventions in the food system, and an interrogation of the role of the designer in such relationships. Such reinforcement of the intellectual and social context of the work, illustrating its intersection with a larger conversation, was a significant pedagogic move, underscoring the university as a locus of possibility, not completion. Being exploratory meant that many of these exhibits were created specifically for the gallery, and often we worked with our colleagues and students to translate their projects into an exhibitable form. A sample of exhibits includes the following.

\section{Bronxscape}

Parsons architect David Lewis worked with students and colleagues on Bronxscape, an urban rooftop garden and outdoor kitchen in the Bronx for young adults transitioning out of foster care. The exhibit, with a model and photographs of the design-build project, illustrated how a physical site for food-related activities might serve to infuse a sense of community among its users.

\section{Corbin Hill Road Farm}

Three videos mapped the complex network that is professor of nonprofit management Dennis Derryck's Corbin Hill Road Farm, an innovative community supported agriculture model that connects low-income South Bronx residents, largely African American and Latino, to rural farms through an eventual ownership stake in the land (see Cohen \& Derryck, 2011). The videos, produced by a film student and installed in triptych, connected Derryck speaking about his design
Figure 4. Students Exploring Living Concrete Exhibits

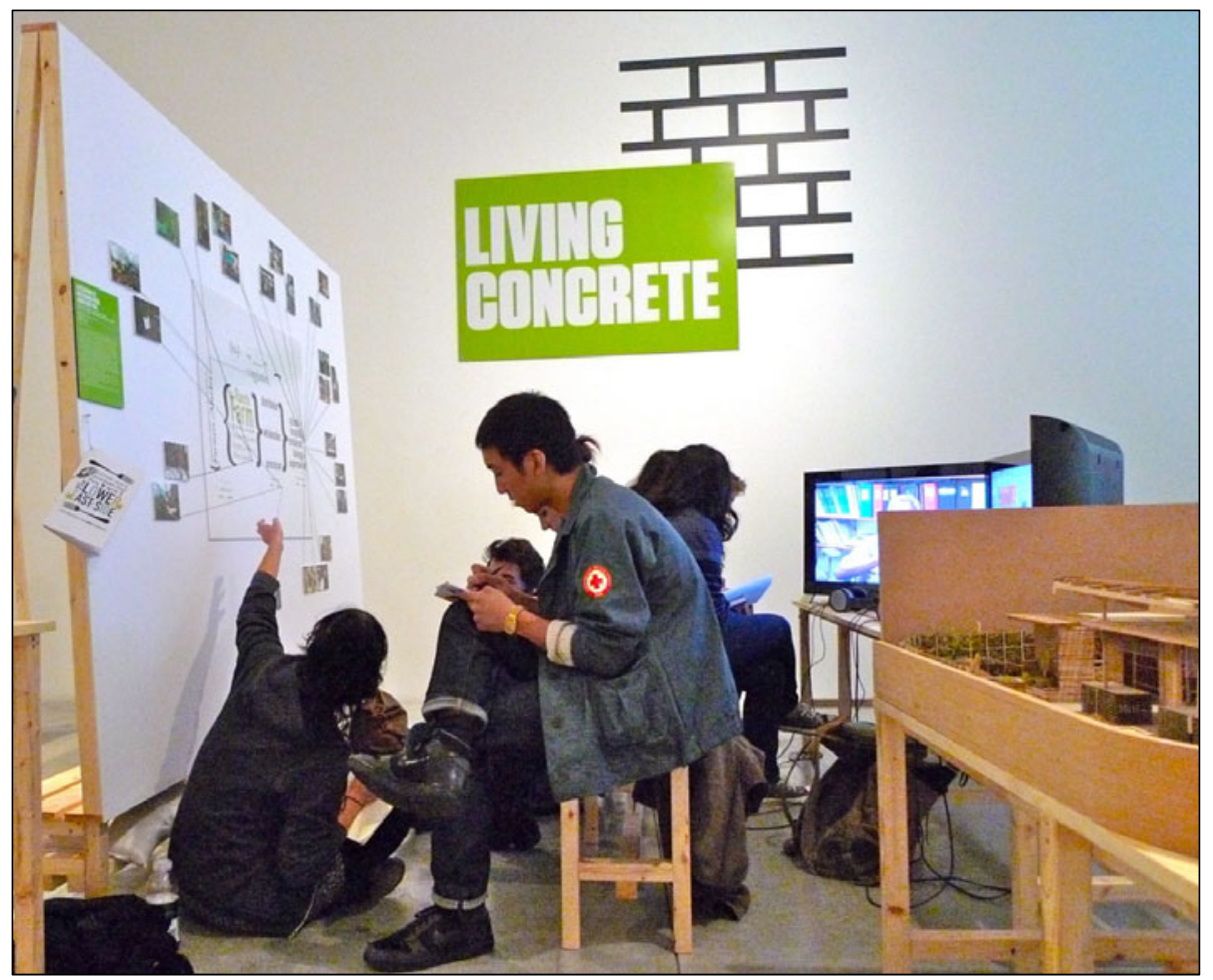


Figure 5. Five Borough Farm Exhibit

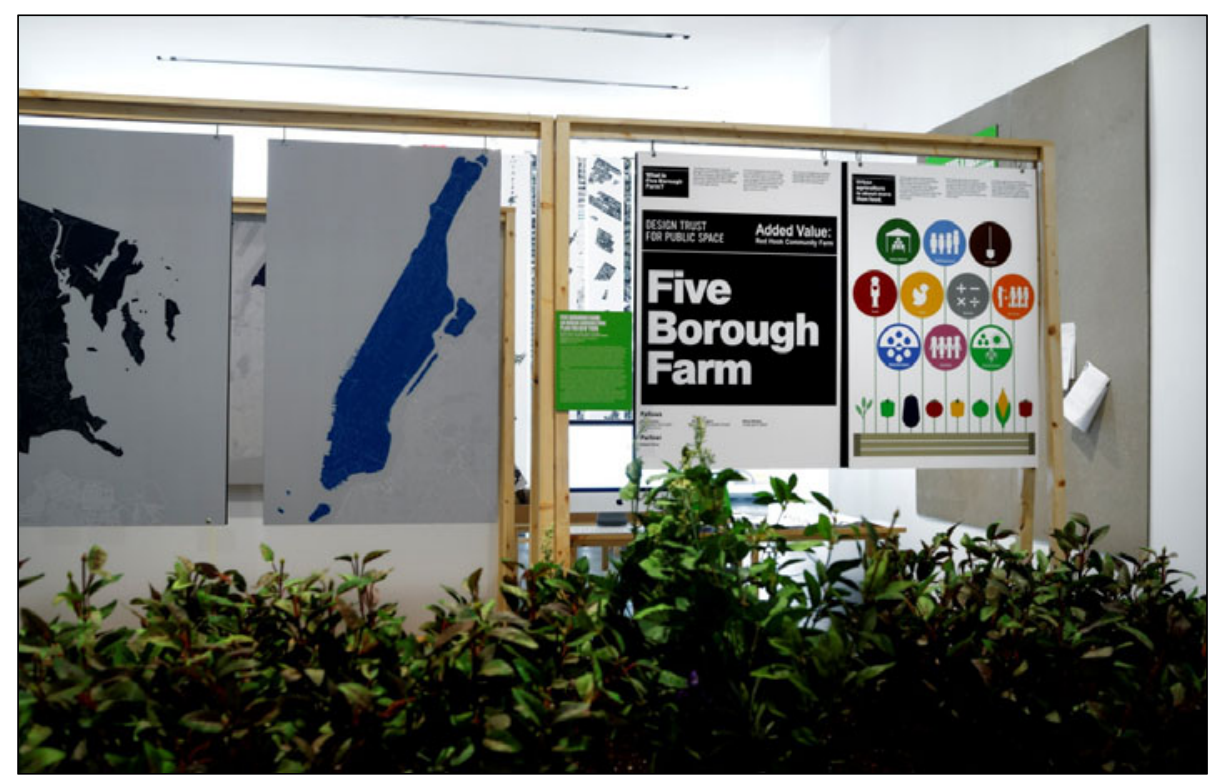

Mapping Projects

Four exhibits illustrated the process of mapping the food system, two of which evolved over the course of the exhibition. The Five Borough Farm project, initiated by the Design Trust for Public Space, a multidisciplinary effort to craft a policy plan for urban agriculture in New York, had an interactive element that included visualization in the form of a "decision tree" deliberately designed to be incomplete, of how public policies affect

inspirations and the ongoing challenges to the residents in Hunts Point coming to pick up their weekly farm share, and further, to the farmers in Schoharie County, New York, who delight simultaneously in knowing who eats their vegetables and in the discovery of new markets.

\section{Backwater Frontwaters}

Parsons urban designer Victoria Marshall examined the watercourses that lie hidden beneath our concrete landscape ("backwater") and the path each raindrop travels from source to sea across the built environment ("frontwaters"). In cooperation with Newark's Ironbound Community Corporation and Newark Planning Department, as well as the Union Square Partnership and The New School, the installation featured the design interventions created by students to change the function, structure, and meaning of these two patches of the urban ecosystem, building a garden for a natural dye micro-economy at The New School and a community garden in Newark. Hung as a cascading set of strips that mapped changes over time, giant scrolls displayed a series of large-scale maps, while slender film-like strips functioned as small-scale photo documentation. whether, where, and what one can farm in New York City. Visitors could submit their own questions about growing food in New York City that New School students (and other experienced visitors) researched and answered.

A related exhibit was an urban agriculture mapping project in which students in Nevin Cohen's environmental studies course met weekly in the gallery to plot the gardens, farms, compost sites, and interconnected organizations supporting urban agriculture in New York. Over the course of the semester, large maps of the boroughs were gradually filled with markers that reveal the complex web of people, spaces, creatures, and things that compose the city's food system.

\section{A Field Guide to Sustainable Food on the Lower East} Side was researched, written, and designed by New School undergraduates for a class in food systems. It provided residents and visitors a map of the food production, distribution, and composting sites that make up a community that in the 1970s turned many vacant lots into vibrant community gardens. Armed with the guide, a visitor could tramp a few square blocks and follow the arc of a tomato from community garden plot to cookout. 
Farming Concrete, directed by researcher Mara Gittleman with New School students and volunteers, aimed to quantify the food produced by community gardens in New York City. More than merely counting beans, the project also engaged gardeners in thinking about their parcels in relation to the entire gardening network in the city. The resulting interactive website, together with the logs and diagrams developed by the researchers and gardeners, was on display, presenting a picture of an interconnected community of food producers with diverse and idiosyncratic interests, tastes, and garden patches. ${ }^{5}$

\section{Honeybee Projects}

The honeybee made both a literal (albeit virtually so) and imaginative entry into the gallery. A bee-cam provided a live, 24-hour video feed of the out-of-hive activities of the bees of Eagle Street Rooftop Farm in Greenpoint, Brooklyn. Considering the relationship between the honeybee and humans was SPRAWL: COLONY, a sound performance composed by Media Studies faculty member Melissa Grey, which explored the audio frequencies of human communication that disrupt the lives of honeybees, highlighting the impact of humans on insects and other fauna. In addition to this, we included an extract from Insectopedia, a book by Hugh Raffles (2010), New School anthropologist and insectopedist, commenting on the urban bee and describing the intensely communal, communicative, social nature of bees while also arguing that

${ }^{5}$ See http://harvest.farmingconcrete.org/
Photo: Nevin Cohen

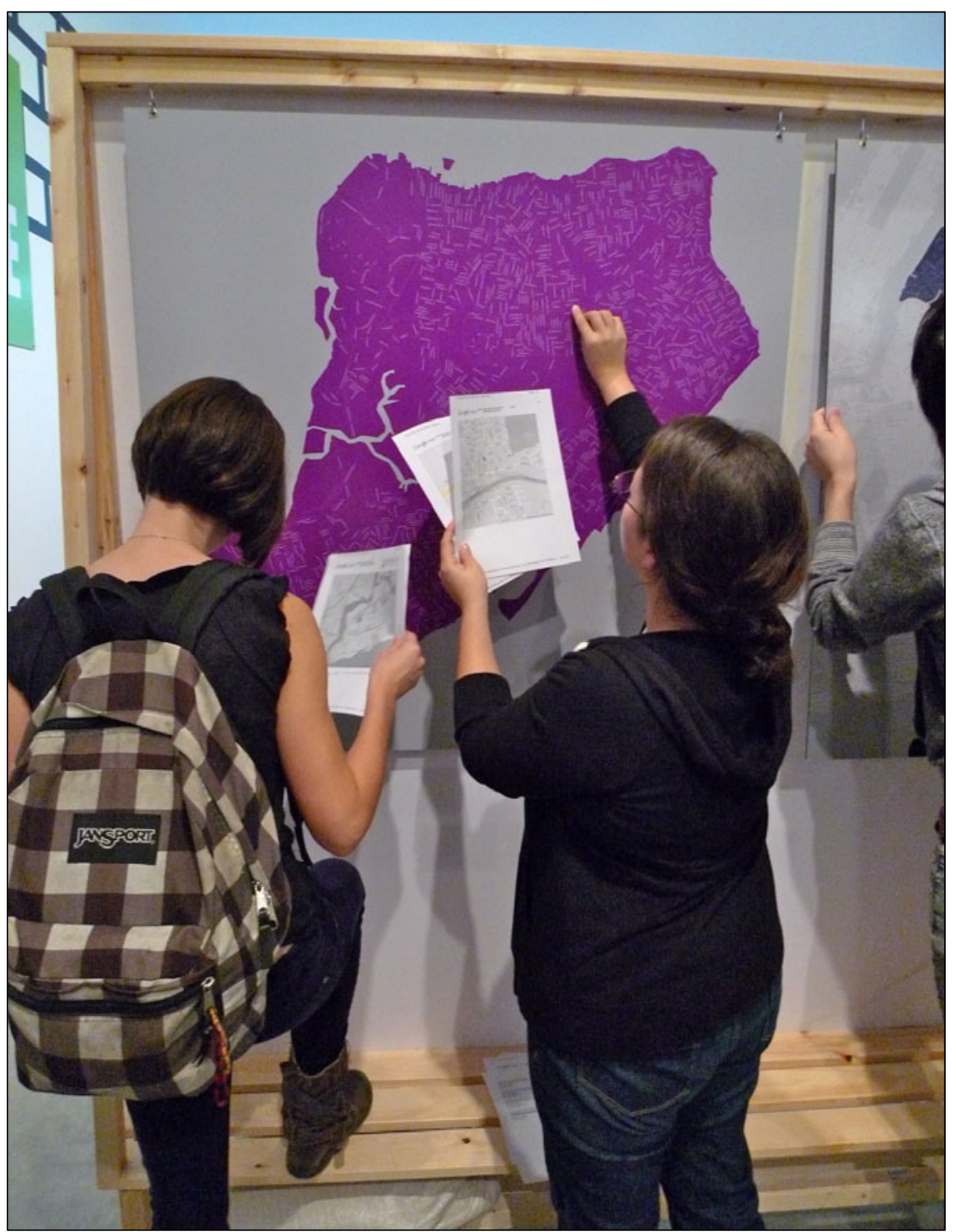

if we bring bees more closely into our lives, they may help us to build community and retain some of the sparkle of urban life.

\section{Carrot City Exhibits}

The edition of Carrot City that we incorporated in our exhibition, collaboratively created with the curators from Ryerson University, included items selected to represent the possibilities of integrating urban agriculture into the city's infrastructure, potentially transforming our very relationship to food and water, dissipating systemic inconsistencies, inequities, and insecurities. We included those 
Figure 7. Examining Carrot City Cases Online

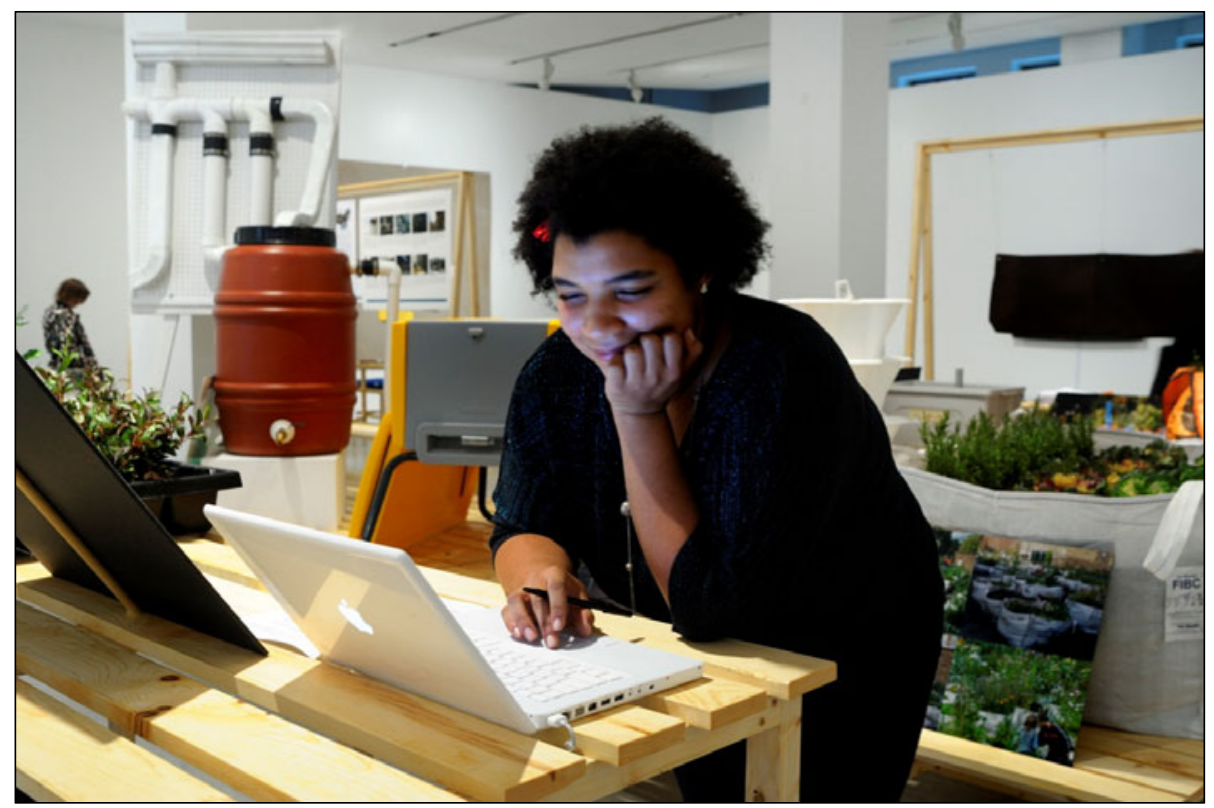

Photo: Martin Seck

\section{venture in East New}

dening and greenmarket

York.

"Creative Action and Everyday Urban Agriculture" explored what it means for individuals in communities to engage in creative practice to reconsider their relationship to food production, neighbors, and environment through urban agriculture, and the resulting physical engagement with place that growing food requires. The panelists included an urban historian, anthropologist,

projects which focused on using design at various scales to support, replicate, and amplify existing fine-grained, human-scale interlinkages of food, farming, and communities. For those interested in more, the entire catalogue could be viewed digitally on a monitor.

\section{Public Programming}

To encourage participation, we organized nine weekly panel discussions on varied topics. Artists Eve Mosher and Tattfoo Tan, urban agriculture activist and chair of the NYC Community Garden Coalition, Karen Washington, and Annie Novack, a professional rooftop farmer, along with other scholars, practitioners, provocateurs, and innovators, came together in lively conversation on Wednesday evenings.

Our first panel discussion, on "Food, Design and Social Change," investigated how design thinking, the integration of problem-solving analytical and prototyping methods used by designers and planners, can be applied to urban agriculture to solve critical social problems, from inequitable access to healthy food to the development of social capital within low-income communities. The radically innovative approaches ranged from neighborhood farms on asphalt playgrounds and rooftops to an interconnected community gar- architect, and two artists.

A Seattle policy-maker, a Chicago social entrepreneur, and an architect from Detroit discussed the role of neighborhood and urban-scale agriculture in community development as part of a panel on national initiatives. They shared examples of community gardens in public housing developments, neighborhood plans for food-based economic development, and a scheme to provide employment for former addicts through large-scale urban agriculture.

Urban soil was a through-line through these disparate discussions. Attendees raised questions about soil and compost consistently regardless of the week's topic or the background of the panelists. Inevitably, one or more audience members would ask about soil toxicity, the possibilities of composting organic waste, various soil amendments and fertilizers, and the politics of access to healthy soils and composts.

Additional events included five informal brown-bag discussions and visits by six New School classes. The students of Parsons Product Design professor Robert Kirkbride, who had been studying the effects of population growth, food, and sustainability, prepared a special dinner (served with tableware they had designed and on tables designed by past students) for 30 invited guests 
in the food systems research, policy, and practice fields to discuss issues surrounding this critical topic. We also opened the gallery as a meeting space to various groups working on food system issues, such as New York City Food Systems Network, which held its annual end-ofyear meeting there, to an organization of women developers exploring the role of food-producing sites in affordable housing projects.

\section{Conclusions: Some Implications for Higher Education \\ Living Concrete/Carrot City} was as much about the urban university and the role it can play in the city as it was about food and urban agriculture. While we did not survey the gallery visitors for their reactions to the exhibition, we observed several important outcomes for The New School, the urban agriculture community in New York, and the nascent field of food studies. Through our reflection on this particular case, we suggest that there may be some useful implications for consideration by other institutions of higher education, particularly those with urban campuses and a commitment to civic engagement.

\section{Colleges and Universities}

Two years earlier, The New School had created a series of thematic interdisciplinary cross-divisional programs in environmental, global, and urban studies that spanned design, science, and the social sciences. Just prior to Living Concrete's opening, The New School hired a new director of the university's food studies program with the aim of growing the curriculum into a full-fledged major. This flush of interest was buttressed by the exhibition, which supported the university's goal of advancing crossdisciplinary pedagogy and creative practice, partic-
Photo: Martin Seck

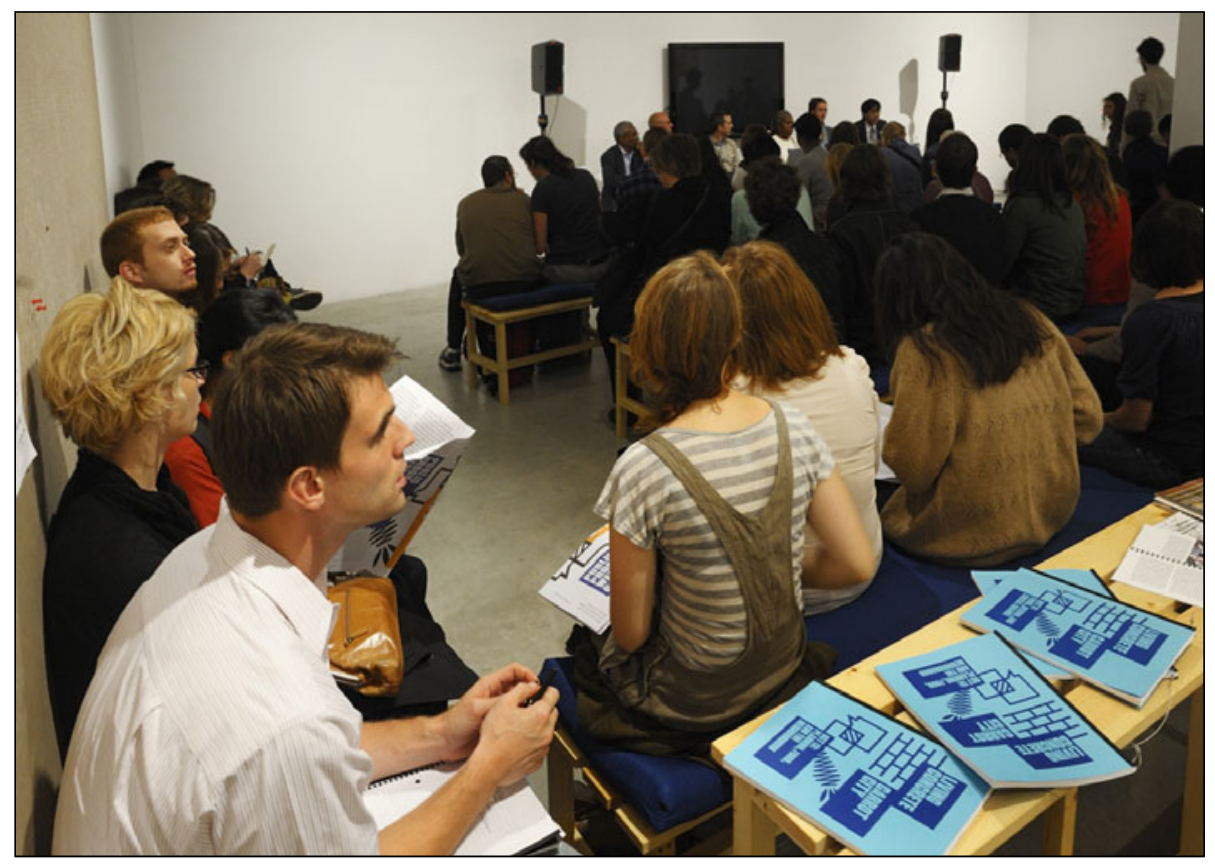

ularly across the design and liberal arts schools.

Could other venues have served to bring faculty and students together? In recent years, the curatorial field has evinced what has been called "an educational turn," 6 an active interest in the cross-pollination of pedagogic and artistic strategies. A productive re-exploration of the place of the gallery and of educational institutions such as the university, the library, and the archive, this "turn" animates newer forms of interaction and engagement among them. What would it mean for diverse disciplines and institutions to engage in a line of inquiry together? With Living Concrete, we sought to explore what it would mean if a university gallery were to provide the curatorial platform for an open-ended research, design, and educational engagement with an issue. Food represented an ideal choice because it elicited a relatively fearless, even opinionated, response from most people alongside a deep investment on their part. Most people had something to say, and even more

\footnotetext{
${ }^{6}$ See O’Neill \& Wilson (2010) for a useful anthology of commissioned essays and significant writing on this front.
} 
importantly, most people felt they had something to learn.

The exhibition also made evident to us that education may not necessarily be held close to the university vest, especially when individuals and groups, charged by various political, social, economic, and environmental concerns, are eagerly exploring mechanisms for teaching and learning. Several of those - unaffiliated with any educational institution - who attended the talks and panels and participated in the discussions, treated the series as a curriculum, making notes, reviewing the readers, and raising questions from one session to the next. We suggest that exhibitions and galleries with public outreach have the potential to serve such self-organized pedagogies, providing at least one point of entry into even the most ivory of towers.

\section{Relationships with the Urban Agriculture Community}

As the exhibition explicitly reached out to those involved in urban agriculture in New York City, people met in the gallery to network, share information, gain inspiration, and create solutions. The weekly panels illustrated the problem-solving potentials of an interconnected urban agriculture system that values the voices of diverse individuals, including artists and designers. The exhibits also provided concrete examples of how urban agriculture projects at various scales offer spaces for civic interaction, whether on the rooftop of a housing project or at the drop-off site for a community supported agriculture venture. We were also reminded that urban agriculture is often as much about building community, re-thinking the nature of public space, and challenging power structures as it is about growing food.

The success of the exhibition rested in part on its casual, invitational nature: the exhibition design, objects, pamphlets, and books encouraged handling, making the gallery a relaxed place in which to work and spend time. We tried to cast the net as widely as possible to attract people working in urban agriculture as speakers and audiences. We advertised the exhibition and public programs through a wide range of organizations, including
Just Food, the NYC Community Gardening Coalition, and individual farmers and gardeners. ${ }^{7}$

The relationships that the exhibition fostered among students and faculty, nonprofit urban agriculture organizations, and farmers and gardeners continue to benefit the urban agriculture community in New York. Since then, The New School has supported student internships on farms and in gardens, hosted additional public programs on urban agriculture, and developed courses about agriculture through service-learning and action research. Faculty members remain engaged in food systems research (like the Five Borough Farm project) and professional practice (like Corbin Hill Road Farm).

\section{Implications for Food Systems Pedagogy}

Complex, multidimensional issues such as those urban farmers and gardeners must address require multidisciplinary approaches. Living Concrete illustrated some of the ways in which design schools and liberal arts colleges such as ours might contribute to the transformation of the food system by fostering cultural and political change and boundary-stretching creative thinking as well as more conventional design and policy innovations. By blending examples of design thinking that emerge from ordinary urban farmers with those of design professionals, we tried to reinforce the idea of a broad-based democratic participation in addressing urban food issues.

Since the exhibition's closing, food-related research has been active at The New School. For example, students in a new Transdisciplinary Design Graduate program spent the spring 2011 semester working with a community development organization in the Hunts Point neighborhood of the South Bronx to study the consumption, transportation, and production of food. They then developed speculative design prototypes of socially, environmentally, and economically sustainable alternative models. Courses in "women in agroe-

\footnotetext{
${ }^{7}$ Nevertheless, The New School's physical distance from many of the city's gardeners, farmers, and food activists, who live and grow food in less dense parts of the city, and its status as a private university, may have discouraged some from visiting or participating in public programs.
} 
cology," "action research and urban agriculture," food writing, the politics of the food system, and many others continue to be offered in different departments across the university. The Food Studies program recently launched a new blog, The Inquisitive Eater, to feature food systems writing from around the university.

At the SJDC, the curatorial agenda of the Living Concrete exhibition remains alive, and food continues to play an active and imaginative part of it. In fall 2011, in a commissioned presentation, artist Michael Cirino of the culinary performance group, a razor, a shiny knife, collaborated with The New School ecologist P. Timon McPhearson to translate the latter's soil assessment data into an edible visualization. ${ }^{8}$ He used modern culinary techniques to evoke the soil structures that affect the trees across the New York boroughs. At the presentation we "ate soil" belonging to several sites in New York City. This is, of course, about food for trees, not for us, but it brought to the table the epistemological role of taste in understanding our world - how might we interact with our environment if our primary filter was our mouth? - and the ways in which we form part of the ecosystem - how our ways of living literally leach into the environment - and linked it to our substrate - soil - all of which were foundational to our concerns in Living Concrete.

\section{References}

Alkon, A. H., \& Agyeman, J. (Eds.). (2011). Cultivating food justice: Race, class, and sustainability. Cambridge: MIT Press.

Cohen, N., \& Derryck, D. (2011). Corbin Hill Road Farm Share: A hybrid food value chain in practice. Journal of Agriculture, Food Systems, and Community Development, 1(4), 85-100. http://dx.doi.org/10.5304/jafscd.2011.014.011

\footnotetext{
${ }^{8}$ Radhika Subramaniam commissioned this project as part of the semester's focus on climate change in conjunction with the exhibition U-n-f-o-l-d: A Cultural Response to Climate Change, curated by David Buckland and Chris Wainwright. Timon McPhearson's study was an assessment of the longand short-term ecological impacts of the Million Trees NYC reforestation efforts. a razor, a shiny knife is a culinary performance group that creates educational, social, and theatrical experiences.
}

Cohen, N., \& Reynolds, K. (2012, April). Policy and research networks and collaborations to strengthen urban agriculture in New York. City. Paper presented at the Agriculture in an Urbanizing Society conference, Wageningen University.

Gorgolewski, M., Komisar, J., \& Nasr, J. (2011). Carrot City: Creating places for urban agriculture. New York: Monacelli Press.

Gottlieb, R., \& Joshi, A. (2010). Food justice. Cambridge: MIT Press.

Hodgson, K., Caton Campbell, M., \& Bailkey, M. (2011). Urban agriculture: Growing healtby, sustainable places. Chicago: American Planning Association.

Lyson, T. (2004). Civic agriculture: Reconnecting farm, food, and community. Lebanon, New Hampshire: Tufts University Press.

McClintock, N. (2010). Why farm the city? Theorizing urban agriculture through a lens of metabolic rift. Cambridge Journal of Regions, Economy and Society, 3(2), 191-207. http://dx.doi.org/10.1093/cjres/rsq005

Morgan, K., \& Sonnino, R. (2010). The urban foodscape: World cities and the new food equation. Cambridge Journal of Regions, Economy and Society, 3(2), 209-224. http://dx.doi.org/10.1093/cjres/rsq007

O'Neill, P., \& Wilson, M. (Eds.). (2010). Curating and the educational turn. London: Open Editions and Amsterdam: de Appel arts centre.

Raffles, H. (2010). Insectopedia. New York: Pantheon. Snider, S. (2010, November 3). Living Concrete/Carrot City: What do you want from your city's soil? [Web $\log$ post]. Retrieved from http://urbanomnibus. net/2010/11/living-concrete-carrot-city/

Tisdall, C. (1979). Joseph Beuys [Exhibit catalog]. New York: Solomon R. Guggenheim Museum. 